Article

\title{
High Threshold Voltage Normally off Ultra-Thin-Barrier GaN MISHEMT with MOCVD-Regrown Ohmics and Si-Rich LPCVD-SiNx Gate Insulator
}

\author{
Hsiang-Chun Wang ${ }^{1}\left(\mathbb{D}\right.$, Hsien-Chin Chiu ${ }^{1,2,3, *}$, Chong-Rong Huang ${ }^{1}$, Hsuan-Ling Kao ${ }^{1,2}{ }^{\oplus}$ and \\ Feng-Tso Chien ${ }^{4}(\mathbb{D}$ \\ 1 Department of Electronics Engineering, Chang Gung University, Taoyuan 333, Taiwan; \\ smallflgt@hotmail.com (H.-C.W.); gain525252@gmail.com (C.-R.H.); snoopy@mail.cgu.edu.tw (H.-L.K.) \\ 2 Department of Radiation Oncology, Chang Gung Memorial Hospital, Taoyuan 333, Taiwan \\ 3 The College of Engineering, Ming Chi University of Technology, Taishan 243, Taiwan \\ 4 Department of Electronics Engineering, Feng-Chia University, Taichung 407, Taiwan; ftchien@fcu.edu.tw \\ * Correspondence: hcchiu@mail.cgu.edu.tw; Tel.: +886-3-2118800-3350
}

Received: 7 April 2020; Accepted: 8 May 2020; Published: 14 May 2020

check for updates

\begin{abstract}
A high threshold voltage $\left(\mathrm{V}_{\mathrm{TH}}\right)$ normally off GaN MISHEMTs with a uniform threshold voltage distribution $\left(\mathrm{V}_{\mathrm{TH}}=4.25 \pm 0.1 \mathrm{~V}\right.$ at $\left.\mathrm{I}_{\mathrm{DS}}=1 \mu \mathrm{A} / \mathrm{mm}\right)$ were demonstrated by the selective area ohmic regrowth technique together with an Si-rich LPCVD-SiN ${ }_{x}$ gate insulator. In the conventional GaN MOSFET structure, the carriers were induced by the inversion channel at a high positive gate voltage. However, this design sacrifices the channel mobility and reliability because a huge number of carriers are beneath the gate insulator directly during operation. In this study, a 3-nm ultra-thin $\mathrm{Al}_{0.25} \mathrm{Ga}_{0.75} \mathrm{~N}$ barrier was adopted to provide a two-dimensional electron gas (2DEG) channel underneath the gate terminal and selective area MOCVD-regrowth layer to improve the ohmic contact resistivity. An Si-rich LPCVD-SiN $\mathrm{x}_{\mathrm{x}}$ gate insulator was employed to absorb trace oxygen contamination on the GaN surface and to improve the insulator/GaN interface quality. Based on the breakdown voltage, current density, and dynamic $\mathrm{R}_{\mathrm{ON}}$ measured results, the proposed LPCVD-MISHEMT provides a potential candidate solution for switching power electronics.
\end{abstract}

Keywords: normally off; MISHEMT; MOCVD-regrowth; leakage current; dynamic $\mathrm{R}_{\mathrm{ON}}$

\section{Introduction}

In recent years, GaN-based normally off high-electron-mobility transistors (HEMTs) have been implemented for switching power electronics due to their wide energy bandgap, high electron mobility, and high current density [1-3]. In order to achieve the normally off operation of the GaN HEMT structure, many papers have reported a recessed gate (e.g., fully removed AlGaN barrier beneath the gate region) and metal-insulator-semiconductor (MIS) gate structure process [4-7]. By controlling the etching depth and profile aspect ratio, a stable positive threshold voltage $\left(\mathrm{V}_{\mathrm{TH}}\right)$ can thus be obtained. In addition, the MIS gate structure also offers high thermal stability of $\mathrm{V}_{\mathrm{TH}}$ and a large forward gate-voltage operating range [8]. However, the deep level traps were generated on AlGaN or GaN surfaces by plasma bombardment damages, which caused the serious $\mathrm{V}_{\mathrm{TH}}$ variation and reliability issue [9]. To overcome the etching damages and $\mathrm{V}_{\mathrm{TH}}$ uniformity issues of the gate-recess-type normally off GaN HEMT, ultra-thin-barrier (UTB) AlGaN/GaN heterostructures with an MIS gate architecture were also proposed [10-12]. All of these previous studies adopted PEALD (plasma-enhanced atomic layer deposition) as the gate insulator to minimize the plasma-induced damage during gate insulator 
deposition. However, the PEALD-grown $\mathrm{Al}_{2} \mathrm{O}_{3}$ is very sensitive to the subsequent process temperature. C. Mizue et al. observed that the as-deposited $\mathrm{ALD}-\mathrm{Al}_{2} \mathrm{O}_{3}$ thin film performed an amorphous-phase structure and the thin film also achieved a uniform thickness at this stage, owing to its deposition mechanism. During the ohmic contact formation process, the $850-900{ }^{\circ} \mathrm{C}$ annealing temperature leads to the formation of a microcrystallized $\mathrm{Al}_{2} \mathrm{O}_{3}$ layer, resulting in an obvious increase in the leakage current of the $\mathrm{Al}_{2} \mathrm{O}_{3} / \mathrm{GaN}$ structure $[13,14]$. In this study, we proposed an Si-rich $\mathrm{SiN}$ gate insulator grown by LPCVD (low-pressure chemical vapor deposition system) to absorb the oxygen atom on the native $\mathrm{AlGaN}$ barrier layer surface and thus narrow the oxygen contamination region between $\mathrm{SiN}_{\mathrm{x}} / \mathrm{AlGaN}$ interfaces. To further improve the ohmic contact resistivity, the MOCVE-regrown AlGaN drain/source regions were also adopted to demonstrate a low on-resistance $\left(\mathrm{R}_{\mathrm{ON}}\right)$ ultra-thin barrier (UTB) GaN MISHEMT with a large positive $\mathrm{V}_{\mathrm{TH}}$ performance.

\section{Device Fabrication}

The devices were fabricated using an AlGaN/GaN heterostructure, grown by metal-organicchemical vapor deposition (MOCVD) on a conductive 6-inch Si (111) p-type substrate. As shown in Figure 1, a 4- $\mu \mathrm{m}$-thick AlN transition layer and C-doped buffer layer were first grown on an $\mathrm{Si}$ substrate for high breakdown voltage consideration. Then, an undoped 300-nm GaN channel layer was deposited on a 50-nm-thick low Al mole fraction $(\mathrm{A} \%=5 \%)$, AlGaN back barrier layer, and a 3-nm-thick undoped $\mathrm{Al}_{0.25} \mathrm{Ga}_{0.75} \mathrm{~N}$ ultra-thin barrier layer were sandwiched into a 1-nm $\mathrm{GaN}$ cap layer and $\mathrm{GaN}$ channel. The GaN cap was used to suppress the oxidation of the $\mathrm{Al}_{0.25} \mathrm{Ga}_{0.75} \mathrm{~N}$ thin barrier and the cap layer at the regrowth region was removed. As to the device fabrication, the device started with the $\mathrm{AlGaN}$ regrowth region formation. Prior to the regrowth process, a 100-nm-thick dense $\mathrm{SiO}_{2}$ layer was deposited on the GaN wafer as a regrowth mask by PECVD and the regrowth region was patterned using diluted $\mathrm{HF}$ wet etching solution. Then, the 1-nm GaN cap layer was removed by low-damage $\mathrm{SF} 6+\mathrm{BCl}_{3}$ mixtures in a dry etching process with a very low DC power condition and the sample was loaded into MOCVD without a queue time. Different from the published regrowth method with ohmic recess [15,16], the additional $20 \mathrm{~nm}$ of $\mathrm{Al}_{0.25} \mathrm{Ga}_{0.75} \mathrm{~N}$ was selectively grown on the exposed 3-nm $\mathrm{Al}_{0.25} \mathrm{Ga}_{0.75} \mathrm{~N}$ barrier layer surface. The $\mathrm{Al}$ composition of the regrown $\mathrm{Al}_{0.25} \mathrm{Ga}_{0.75} \mathrm{~N}$ layer was also $25 \%$ to achieve a high-quality regrowth interface and good contact resistance with the initial barrier layer. This structure exhibited a sheet charge density of $1.05 \times 10^{13} \mathrm{~cm}^{-2}$ and electron mobility of $1570 \mathrm{~cm}^{2} / \mathrm{V} \cdot \mathrm{s}$ at $300 \mathrm{~K}$ together with an epitaxial sheet resistance of $420 \Omega / \square$ measured by Hall measurement. The first step in determining carrier mobility is to measure the Hall voltage by forcing both a magnetic field perpendicular to the sample and a current through the sample. The resistivity can be determined using either a four-point probe on $\mathrm{GaN}$ test samples. The $\mathrm{PECVD} \mathrm{SiO}_{2}$ in the gate region was then selectively removed using diluted HF wet etching. Afterward, the active region was protected by a photoresist and the mesa isolation region was removed in a reactive ion etching (RIE) chamber using $\mathrm{BCl}_{3}+\mathrm{Cl}_{2}$ mixed-gas plasma. As to the gate dielectric layer, a 32-nm-thick layer of Si-rich LPCVD-grown $\mathrm{SiN}_{\mathrm{x}}$ measured by transmission electron microscopy (TEM) was deposited on the 1-nm GaN cap layer. The $\mathrm{SiH}_{2} \mathrm{Cl}_{2}$ (dichlorosilane) flow rate was $150 \mathrm{sccm}$ together with the mixture gas flow ratio $\left(\mathrm{SiH}_{2} \mathrm{Cl}_{2}\right.$ : $\mathrm{NH}_{3}$ ) of 5:1 to reach an Si-rich content in $\mathrm{SiN}_{\mathrm{x}}$ at $800^{\circ} \mathrm{C}, 180 \mathrm{~m}$ torr environment, and the deposition rate was around $2.2 \mathrm{~nm} / \mathrm{min}$. For comparison, the device with a 30-nm PECVD-grown $\mathrm{SiN}_{\mathrm{x}}$ gate dielectric was also fabricated. The ohmic contacts for the drain and source contacts were deposited by the electron beam evaporation of a multi-layer Ti/Al/Ni/Au $(30 \mathrm{~nm} / 125 \mathrm{~nm} / 50 \mathrm{~nm} / 200 \mathrm{~nm})$ sequence, followed by rapid thermal annealing at $550{ }^{\circ} \mathrm{C}$ for $20 \mathrm{~min}$ in a nitrogen-rich ambient. Finally, the electron-beam evaporated $\mathrm{Ni} / \mathrm{Au}$ was deposited as gate metal. Compared to the conventional gate recessed-type E-mode HEMT process, the barrier layer in this study eliminated the plasma bombardment by dry etching during the device fabrication process. Figure 1 shows the cross-sectional structure and scanning electron microscope (SEM) images of the fabricated UTB GaN MISHEMT with the device dimension $L_{G S} / L_{G} / L_{G D} / L_{F P}$ of $2 / 1.5 / 10 / 4 \mu \mathrm{m}$, respectively. According to the atomic force microscope (AFM) images shown in Figure 2, the root mean square roughness of the $\mathrm{GaN} / \mathrm{Al}_{0.25} \mathrm{Ga}_{0.75} \mathrm{~N} / \mathrm{GaN}$ heterostructure 
beneath the gate metal area is $0.37 \mathrm{~nm}$ and this value is $0.43 \mathrm{~nm}$ of the regrown $\mathrm{Al}_{0.25} \mathrm{Ga}_{0.75} \mathrm{~N}$ ohmic contact area. The ohmic contact resistance measured by the transmission line method (TLM) was improved from $2.2 \times 10^{-5} \Omega-\mathrm{cm}^{2}$ to $1.6 \times 10^{-6} \Omega-\mathrm{cm}^{2}$ by adopting the AlGaN-regrown method owing to its totally 23-nm AlGaN barrier-induced high 2-DEG density.

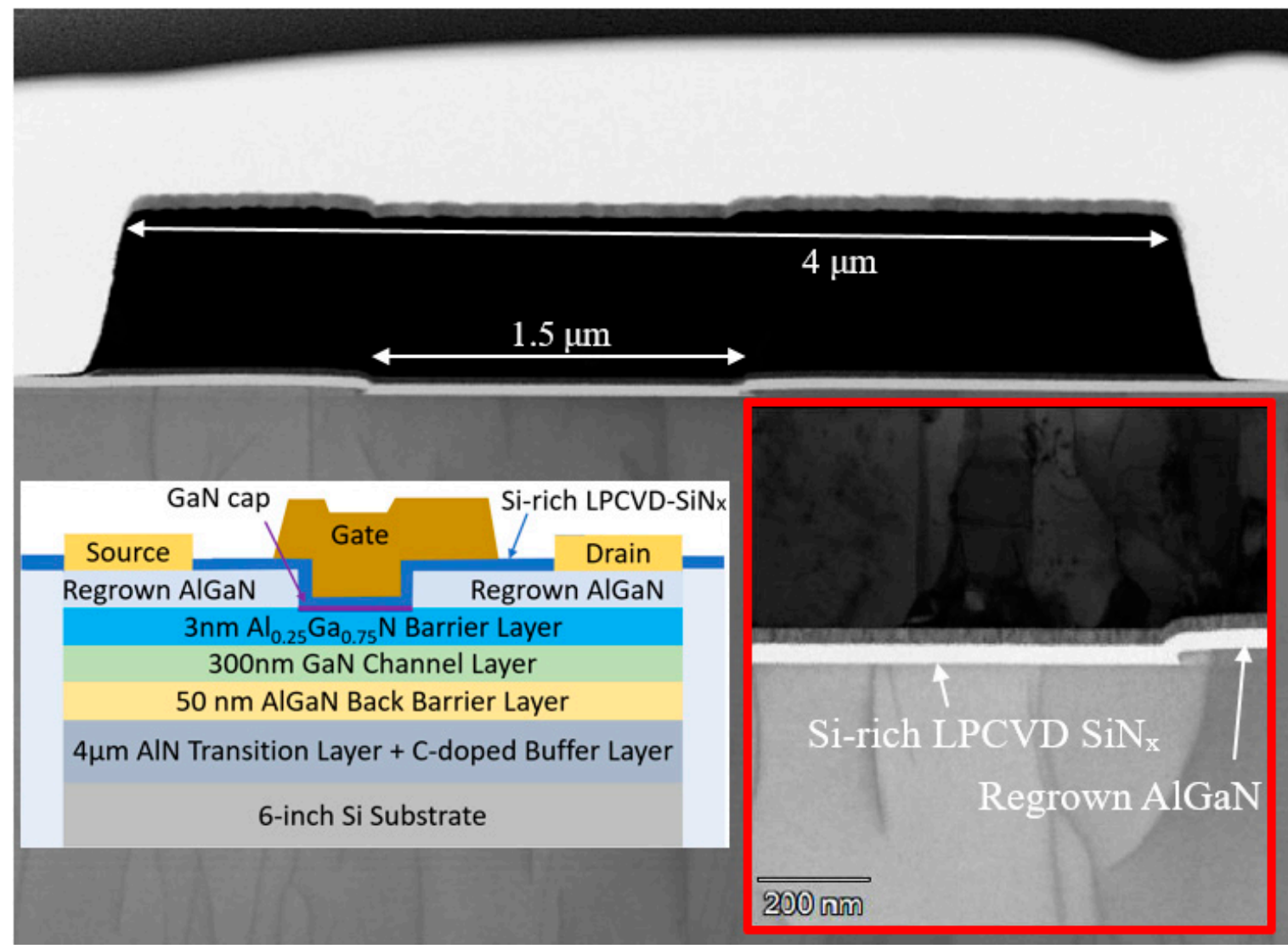

Figure 1. The layer structure and cross-sectional SEM images of Si-rich LPCVD-SiN $\mathrm{N}_{\mathrm{x}}$ MISHEMT with a selective area ohmic regrowth layer.
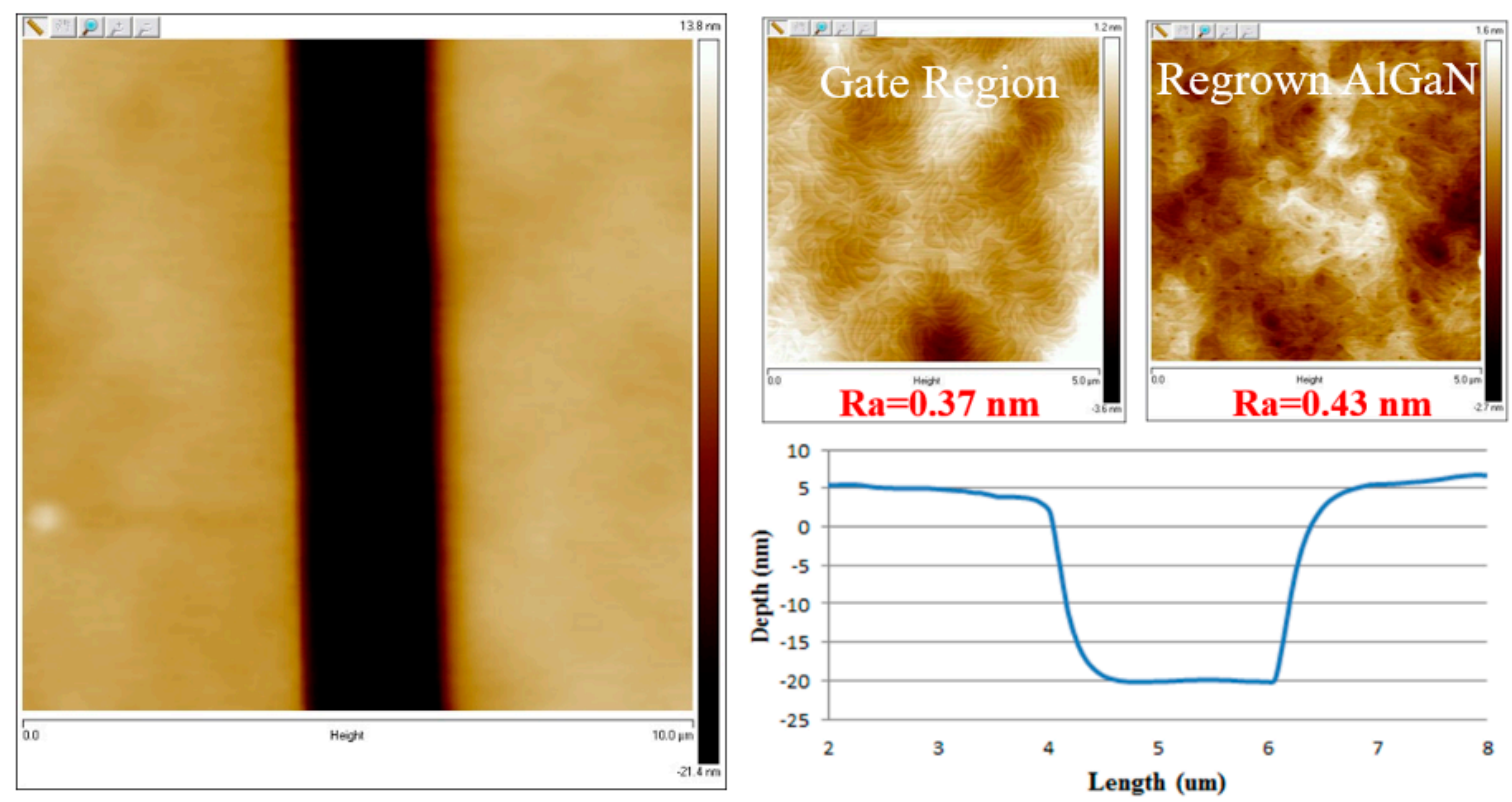

Figure 2. The AFM images gate trench profile before and after selective area ohmic regrowth. 


\section{Results and Discussion}

Figure 3 presents the energy dispersive spectrometer (EDS) vertical line scanning analysis for the PECVD- and LPCVD-SiN $\mathrm{x}_{\mathrm{x}}$ passivated UTB MISHEMT. Obviously, a narrow oxygen-contaminated layer was found on the $\mathrm{AlGaN}$ surface, which was primarily due to the native $\mathrm{AlGaN}$ oxidation compounds with environment moisture. However, with Si-rich LPCVD passivation at high temperature, the oxygen atoms were collected into the SiN layer and the oxygen-contaminated layer for LPCVD-MISHEMT was eliminated [17]. Therefore, Si-rich LPCVD-grown $\mathrm{SiN}_{\mathrm{x}}$ film passivates the dangling bonds on the $\mathrm{Ga}(\mathrm{Al})$-terminated $\mathrm{AlGaN}$ surface, and thus lowers the interface traps in LPCVD-grown $\mathrm{SiN}_{\mathrm{x}}$ passivated UTB MISHEMTs.

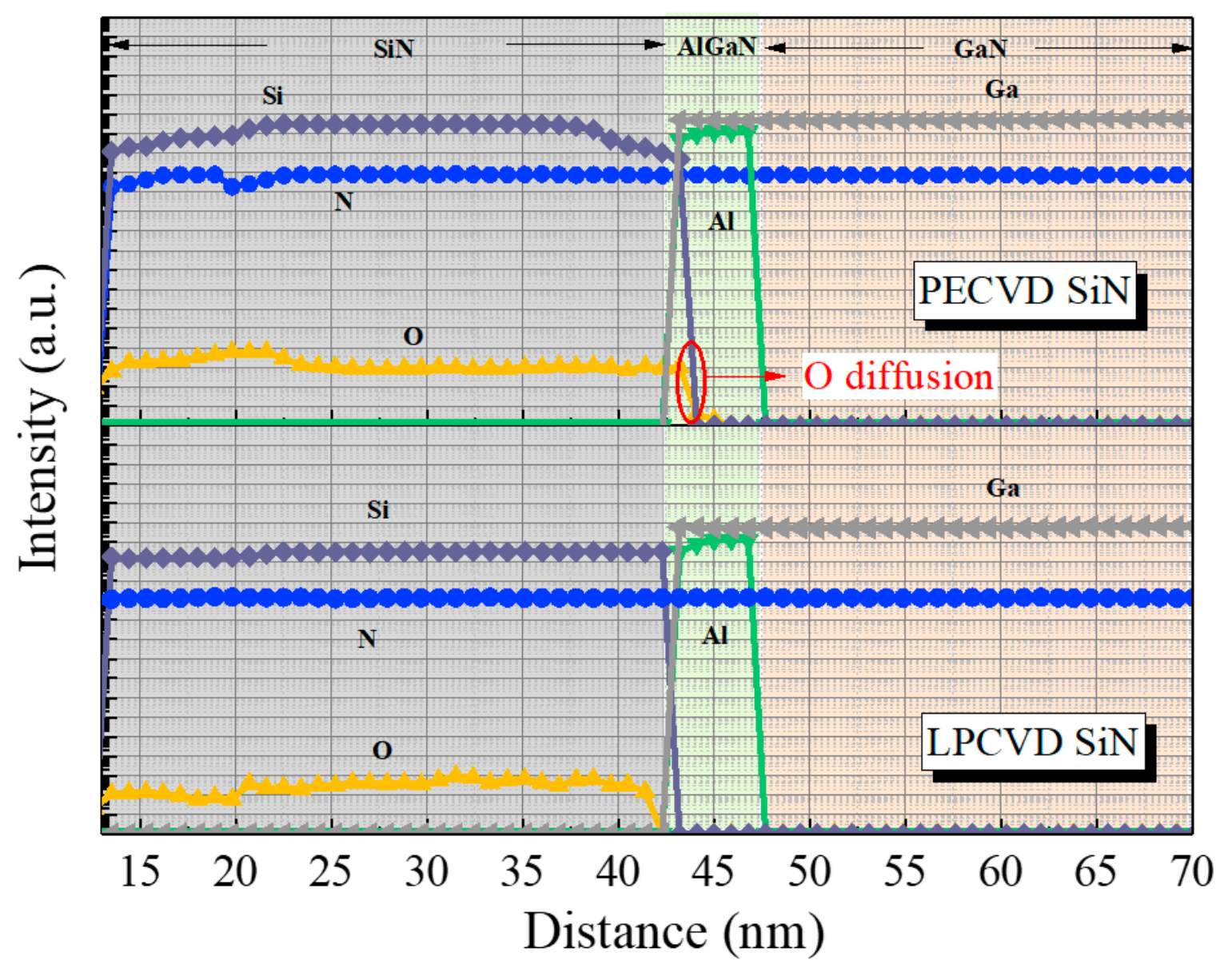

Figure 3. The EDX vertical line scanning images for PECVD- and LPCVD-SiN ${ }_{x}$ passivated UTB MISHEMT.

Figure 4a displays the three-terminal off-state breakdown voltages $\left(V_{\mathrm{BR}}\right)$ of devices with a wide gate-to-drain spacing $(10 \mu \mathrm{m})$, which was evaluated by the Agilent B1505A measurement system and the Si substrate was grounded bias during the measurement. In this study, $V_{\mathrm{BR}}$ is defined as the voltage when the drain leakage current between the source and the drain contacts reaches $1 \mathrm{~mA} / \mathrm{mm}$ at a $V_{\mathrm{GS}}$ of $0 \mathrm{~V}$. The drain $\left(I_{\mathrm{DS}}\right)$ leakage current of PECVD-MISHEMT increases rapidly with the increase of $V_{\mathrm{DS}}$ and its $V_{\mathrm{BR}}$ is $680 \mathrm{~V}$. Referring to the gate $\left(I_{\mathrm{GS}}\right)$ leakage current in Figure $4 \mathrm{~b}$, obviously, the $I_{\mathrm{DS}}$ leakage current was one order of magnitude high than the $I_{\mathrm{GS}}$ leakage current. Thus, the three-terminal leakage current not only contributed by the gate terminal when $\mathrm{V}_{\mathrm{DS}}>50 \mathrm{~V}$ and the surface hopping leakage current also appeared in the breakdown mechanism of PECVD- MISHEMT [7]. The gate leakage current of LPCVD-MISHEMT is negligible and the drain-to-source leakage current dominated the breakdown mechanism in these devices, significantly improving the $V_{\mathrm{BR}}$ values to $750 \mathrm{~V}$. Based on 
the leakage current shown in Figure 4, the Si-rich high-quality LPCVD gate insulator suppressed the surface native oxidation layer and prevented electrons' surface hopping-induced leakage current at a high drain voltage [17].

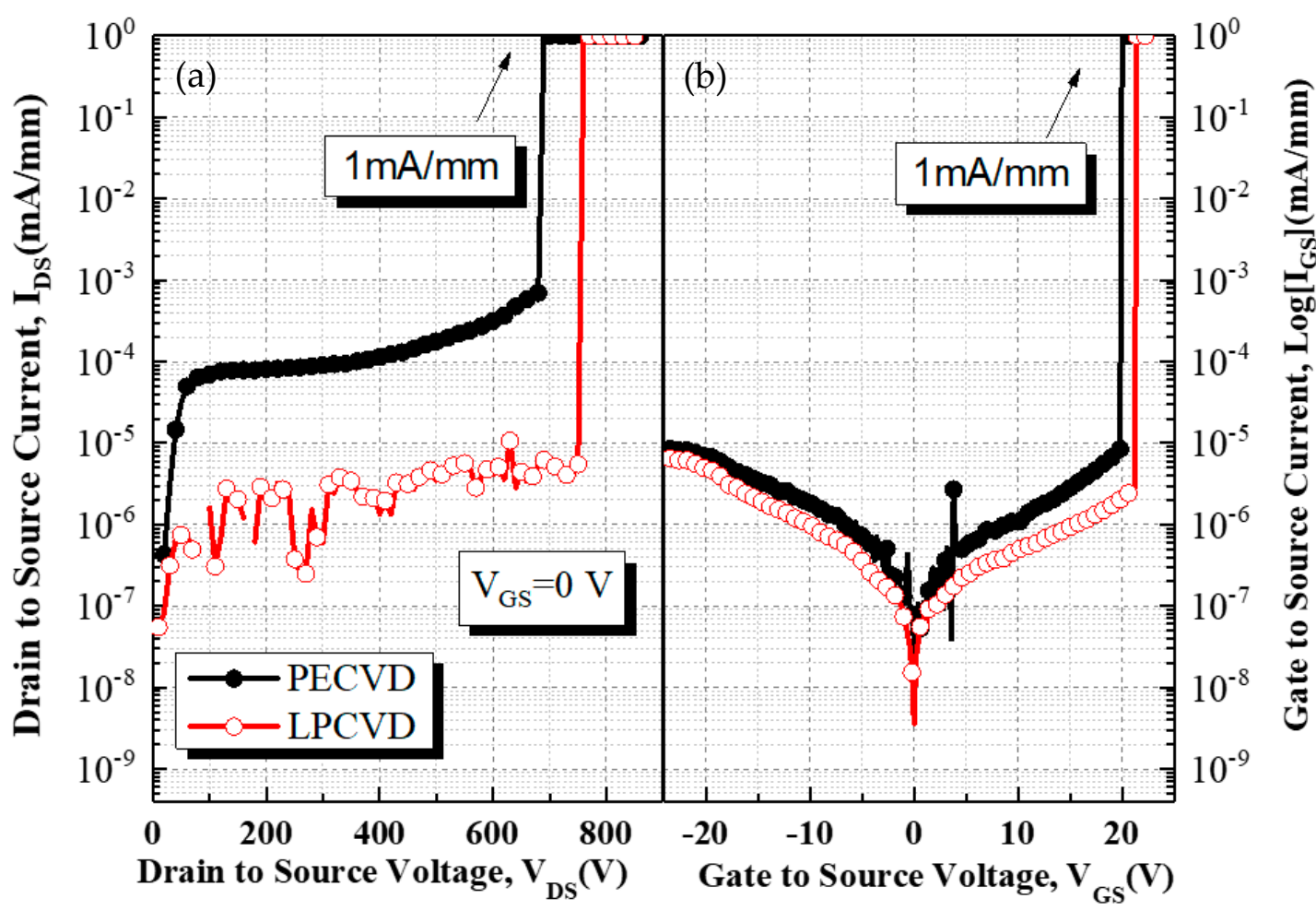

Figure 4. (a)the three-terminal off-state breakdown voltages and $(\mathbf{b}) \mathrm{I}_{\mathrm{GS}}-\mathrm{V}_{\mathrm{GS}}$ characteristics for PECVD-

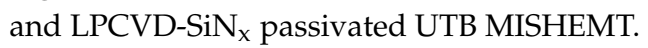

Figure 5 displays the $\mathrm{I}_{\mathrm{DS}}-\mathrm{V}_{\mathrm{DS}}$ outputs and $\log$-scale $\mathrm{I}_{\mathrm{DS}}-\mathrm{V}_{\mathrm{GS}}$ transfer characteristics of two devices at a $\mathrm{V}_{\mathrm{DS}}$ of $10 \mathrm{~V}$. The $\mathrm{V}_{\mathrm{TH}}$ values of the PECVD- and the LPCVD-MISHEMT were both $4.25 \mathrm{~V}$ (defined by $\left.\mathrm{I}_{\mathrm{DS}}=1 \mathrm{~mA} / \mathrm{mm}\right)$. The corresponding maximum drain current density $\left(\mathrm{I}_{\mathrm{Dmax}}\right)$ values were 276.26 and $361.71 \mathrm{~mA} / \mathrm{mm}$, respectively. The $\mathrm{I}_{\text {Dmax }}$ value of the LPCVD-MISHEMT was $30.9 \%$ higher than that of the PECVD-MISHEMT because the capability of the gate modulation-induced current was not limited by the gate leakage current, which appeared in PECVD-MISHEMT. Thus, the static $R_{\text {on }}$ of the LPCVD-MISHEMT was improved to $19.85 \Omega \cdot \mathrm{mm}$, which corresponds to a specific on-resistance $\left(R_{\mathrm{on}} \cdot \mathrm{A}\right)$ of $1.98 \mathrm{~m} \Omega \cdot \mathrm{cm}^{2}$ at a $V_{G S}$ value of $16 \mathrm{~V}$. These values of the PECVD-MISHEMT were $26.78 \Omega \cdot \mathrm{mm}$ and $2.67 \mathrm{~m} \Omega \cdot \mathrm{cm}^{2}$, respectively. For the LPCVD-MISHEMT, the suppression in the off-state IDS leakage current improved the on/off drain current ratio by approximately one order of magnitude and the subthreshold swing slope (S.S.) was improved from 155 to $150 \mathrm{mV} / \mathrm{dec}$ compared with that of the LPCVD-MISHEMT. Owing to the good interface between SiNx and the ultra-thin AlGaN barrier of the LPCVD-MISHEMT, contributing to improve the $\mathrm{V}_{\mathrm{TH}}$ uniformity and controllability. A standard deviation of $0.1 \mathrm{~V}$ was obtained by measuring 50 samples across the 6-inch wafer, as shown in the inset of Figure $4 \mathrm{~b}$.

The quasi-static $\mathrm{C}-\mathrm{V}$ characterization was adopted to capture the carrier filling process of the deep interface states at the MIS gate structure interface of both devices, as shown in Figure 6, which was performed on the MIS gate structure of both devices. The second plateau in the $\mathrm{C}-\mathrm{V}$ characteristics of the MIS diodes depicts the response of the insulator/thin $\mathrm{AlGaN}$ interface states. The interface trap density $\left(D_{i t}\right)$ values with te between $10^{-6}$ and $10^{-4} \mathrm{~s}\left(0.34<\mathrm{E}_{\mathrm{C}}-\mathrm{E}_{\mathrm{T}}<0.42 \mathrm{eV}\right)$ from $5.3 \times 10^{10} \mathrm{~cm}^{-2}$ to $1.2 \times 10^{11} \mathrm{~cm}^{-2} \mathrm{eV}^{-1}$ for LPCVD-MISHEMT were lower than $6.8 \times 10^{10} \mathrm{~cm}^{-2}$ to $2.5 \times 10^{11} \mathrm{~cm}^{-2} \mathrm{eV}^{-1}$ for PECVD-MISHEMT. 


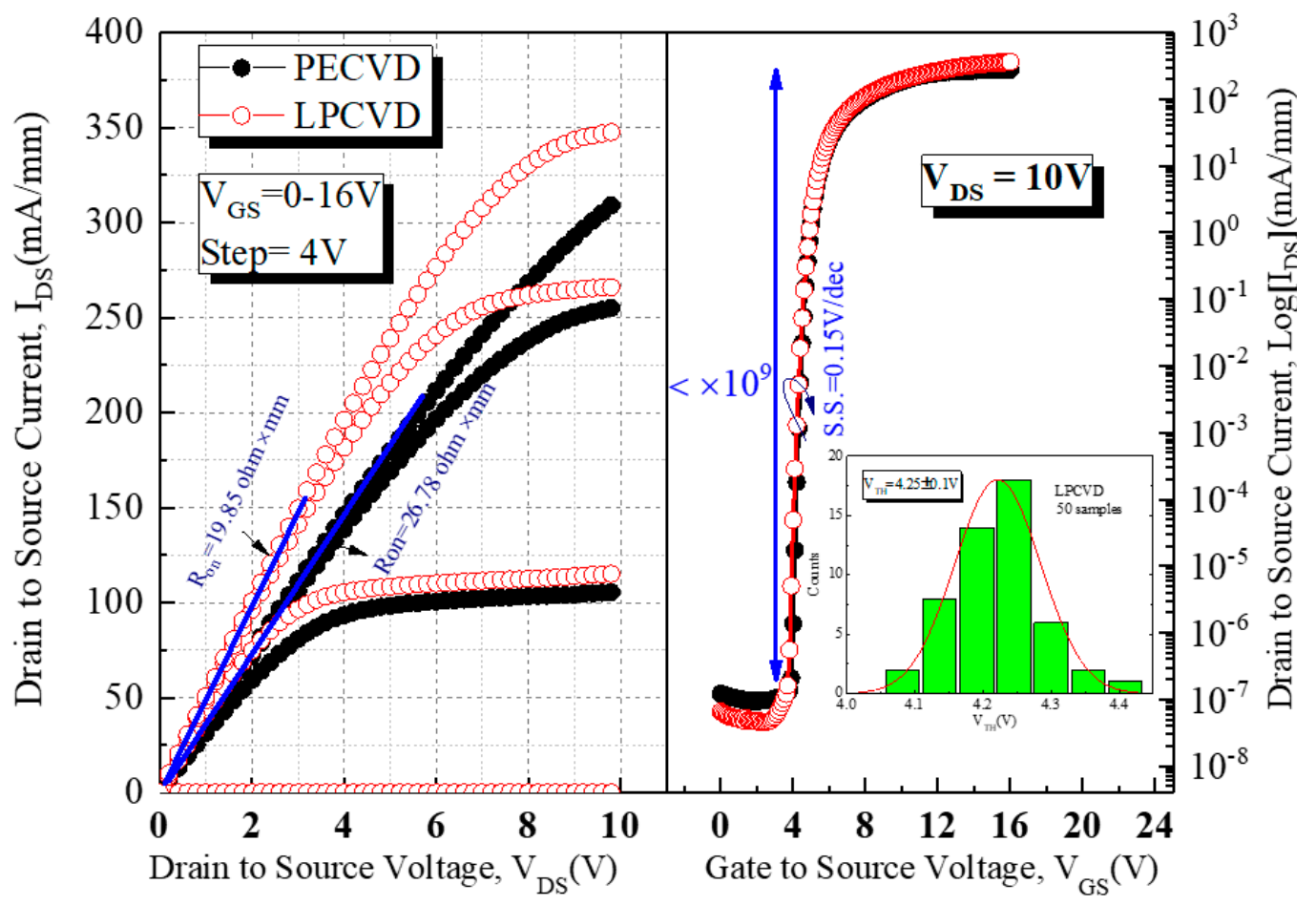

(a)

(b)

Figure 5. (a)The IDS-VDS characteristics (b) Log-scale IDS-VGS and VTH distribution of both devices.

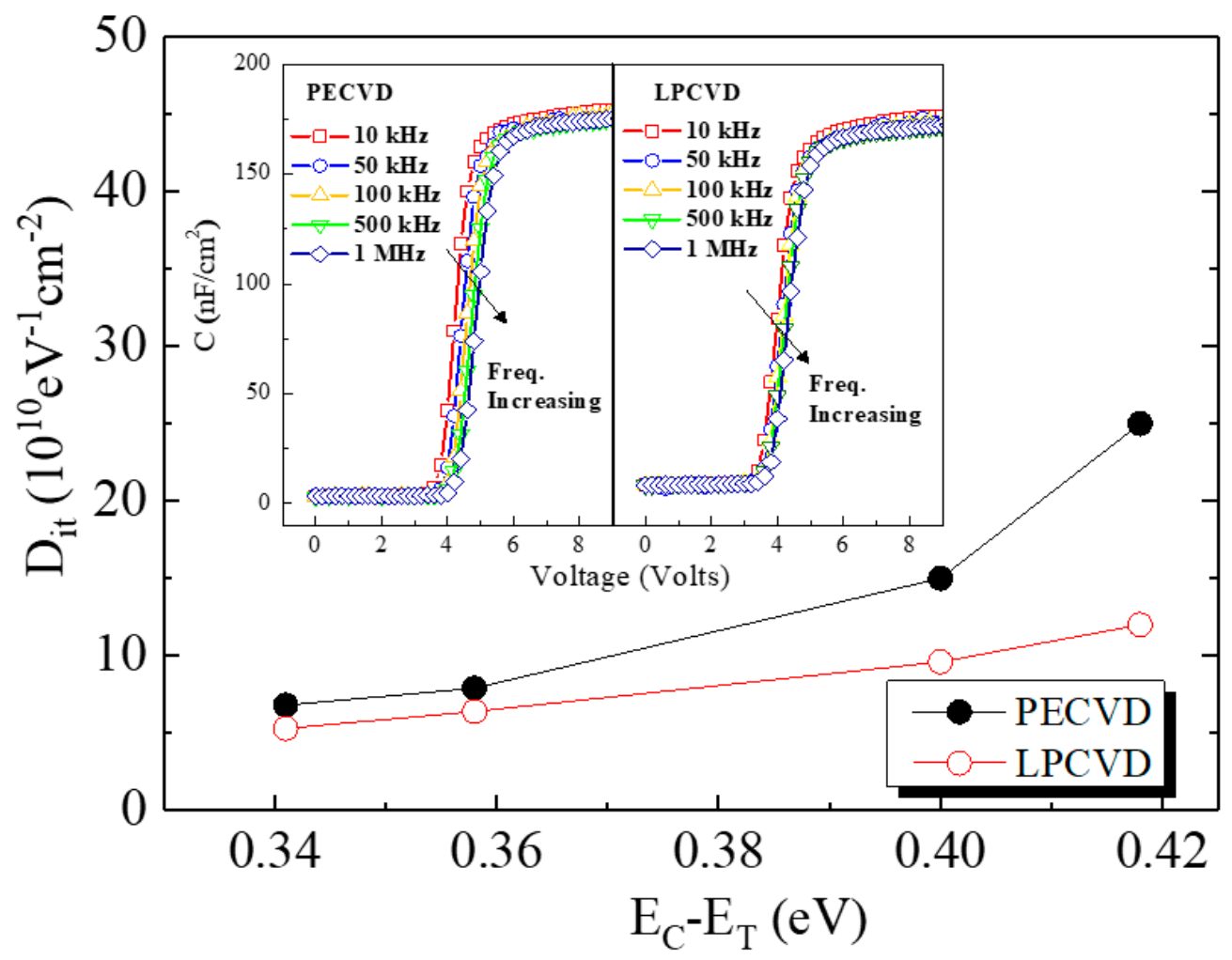

Figure 6. The quasi-static $C-V$ characterization and Dit versus $E_{C}-E_{T}$ of the PECVDand LPCVD-MISHEMT.

To further analyze the trapping/detrapping effect, the dynamic $R_{o n}$ ratio of the PECVD- and LPCVD-MISHEMT was measured using a pulse width of $2 \mu$ s and period of $200 \mu$ s. In this work, 
there were five bias conditions, which are pulse voltage $\left(\mathrm{V}_{\mathrm{GS}}, \mathrm{V}_{\mathrm{DS}}\right)$ and quiescent voltage $\left(\mathrm{V}_{\mathrm{GSQ}}, \mathrm{V}_{\mathrm{DSQ}}\right)$. However, the drain lag is due to the carriers during switching being trapped near the surface, which is in the $\mathrm{SiN}_{\mathrm{x}} /$ thin $\mathrm{AlGaN}$ interface. Furthermore, the trapping phenomenon also leads to a carrier density reduction and then an increase of the resistance. As the result, the $\mathrm{V}_{\mathrm{DSQ}}$ for both devices was swept from 0 to $600 \mathrm{~V}$ with an increment of $100 \mathrm{~V}$, respectively. Clearly, the LPCVD-MISHEMT exhibits a superior dynamic $R_{o n}$ than the PECVD-MISHEMT because the dynamic $R_{o n}$ ratio improved from 2.6 to 1.9 times at $\mathrm{V}_{\mathrm{DSQ}}=600 \mathrm{~V}$, as indicated in Figure 7. In addition, a higher $\mathrm{V}_{\mathrm{DSQ}}$ was applied because of a lower trap density in the MIS-gate interface. The oxygen vacancies in the AlGaN/GaN interface can lead to serious trapping behavior during high switching operation [18].

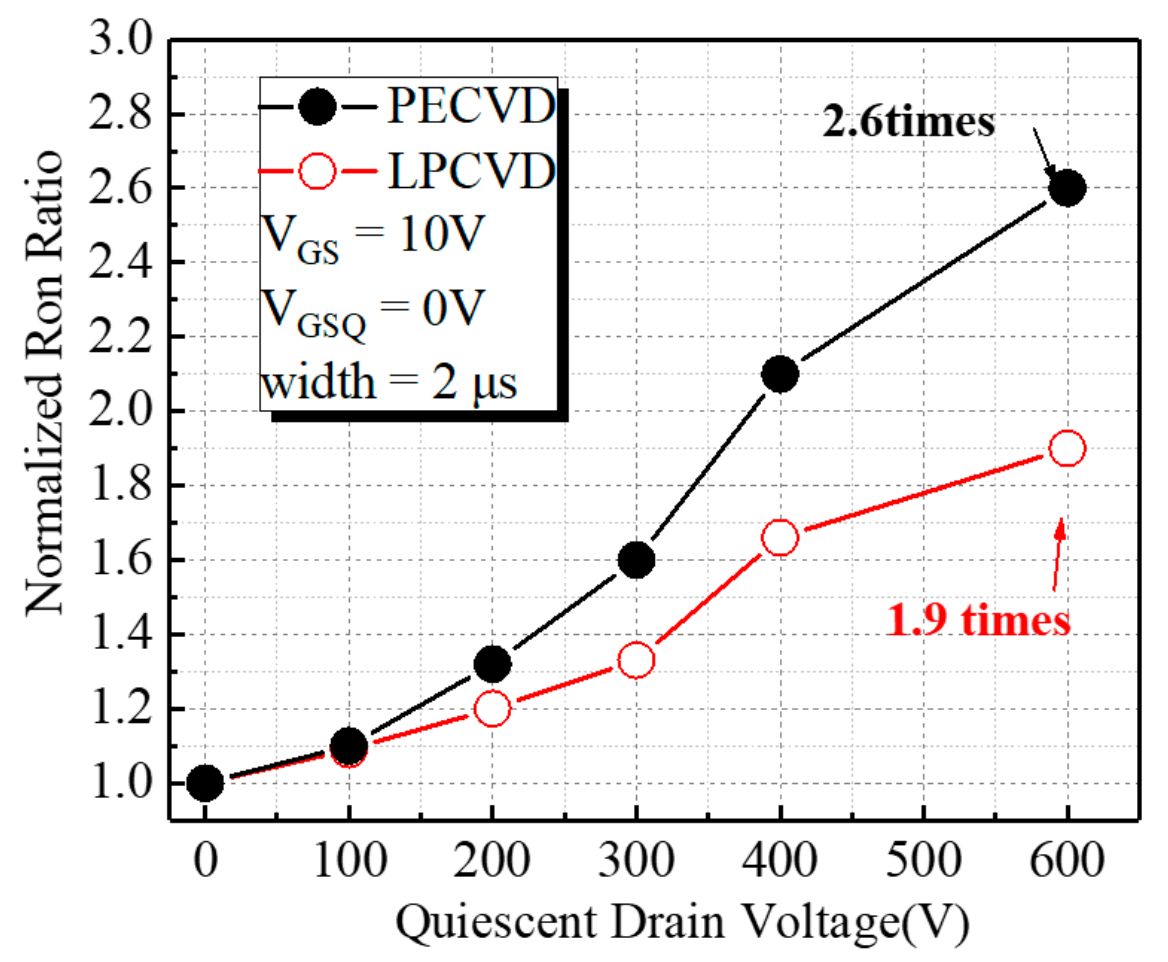

Figure 7. The dynamic $R_{o n}$ ratio of the PECVD- and LPCVD-MISHEMT.

\section{Conclusions}

In this work, we developed and investigated the electrical properties of a normally off GaN-based switching device by using a high-temperature Si-rich LPCVD-SiN $\mathrm{N}_{\mathrm{x}}$ gate insulator and selective area ohmic regrowth technique. Based on the EDX analysis, Si-rich LPCVD-SiN $\mathrm{L}_{\mathrm{x}}$ mitigated the native oxygen contamination of the GaN surface, thus the interface $D_{i t}$ was improved. In addition, the selective area ohmic regrowth AlGaN layer improved the 2-DEG density at the access region, thus the device $\mathrm{R}_{\mathrm{ON}}$ was reduced. The low $\mathrm{D}_{\mathrm{it}}$ high temperature Si-rich LPCVD-SiN $\mathrm{N}_{\mathrm{x}}$ gate insulator achieved a large positive threshold voltage together with a low leakage current and high $\mathrm{I}_{\mathrm{ON}} / \mathrm{I}_{\mathrm{OFF}}$ ratio. Moreover, the low dynamic $\mathrm{R}_{\mathrm{ON}}$ also indicated that the proposed device provides great promise in achieving a high-performance normally off $\mathrm{GaN}$ power electronics device.

Author Contributions: Methodology and Investigation, H.-C.W. and C.-R.H.; Conceptualization, F.-T.C.; Validation, H.-L.K.; Project Administration, H.-C.C. All authors have read and agreed to the published version of the manuscript.

Funding: This work was supported by the Ministry of Science and Technology (MOST), Taiwan, R.O.C., under Grant MOST 108-2218-E-182-006.

Conflicts of Interest: The authors declare no conflict of interest. 


\section{References}

1. Chen, K.J.; Haberlen, O.; Lidow, A.; Tsai, C.L.; Ueda, T.; Uemoto, Y.; Wu, Y. GaN-on-Si Power Technology: Devices and Applications. IEEE Trans. Electron Devices 2017, 64, 779-795. [CrossRef]

2. Uemoto, Y.; Hikita, M.; Matsuo, H.; Ishida, H.; Yanagihara, M.; Ueno, H.; Ueda, T.; Tanaka, T.; Ueda, D. Gate Injection Transistor (GIT) - A Normally-Off AlGaN/GaN Power Transistor Using Conductivity Modulation. IEEE Trans. Electron Devices 2007, 54, 3393-3399. [CrossRef]

3. Marcon, D.; Saripalli, Y.N.; Decoutere, S. 200mm GaN-on-Si epitaxy and e-mode device technology. In Proceedings of the 2015 IEEE International Electron Devices Meeting (IEDM), Washington, DC, USA, 7-9 December 2015; pp. 1621-1624. [CrossRef]

4. Oka, T.; Nozawa, T. AlGaN/GaN Recessed MIS-Gate HFET with High-Threshold-Voltage Normally-Off Operation for Power Electronics Applications. IEEE Electron Device Lett. 2008, 29, 668-670. [CrossRef]

5. Wang, Y.; Wang, M.; Xie, B.; Wen, C.P.; Wang, J.; Hao, Y.; Wu, W.; Chen, K.J.; Shen, B. High-performance normally-Off Al2O3/GaN MOSFET using a wet etching-based gate recess technique. IEEE Electron Device Lett. 2013, 34, 1370-1372. [CrossRef]

6. Wang, H.; Wang, J.; Li, M.; Cao, Q.; Yu, M.; He, Y.; Wu, W. 823-mA/mm Drain Current Density and 945-MW/cm2 Baliga's Figure-of-Merit Enhancement-Mode GaN MISFETs with a Novel PEALD-AIN/LPCVD-Si3N4 Dual-Gate Dielectric. IEEE Electron Device Lett. 2018, 39, 1888-1891. [CrossRef]

7. Huang, S.; Jiang, Q.; Wei, K.; Liu, G.; Wang, X.; Zheng, Y.; Sun, B.; Zhao, C.; Liu, H.; Jin, Z.; et al. High-temperature low-damage gate recess technique and ozone-assisted ALD-grown $\mathrm{Al} 2 \mathrm{O} 3$ gate dielectric for high-performance normally-off GaN MIS-HEMTs. In Proceedings of the 2014 IEEE International Electron Devices Meeting, San Francisco, CA, USA, 15-17 December 2014; pp. 1741-1744. [CrossRef]

8. Tang, Z.; Jiang, Q.; Lu, Y.; Huang, S.; Yang, S.; Tang, X.; Chen, K.J. 600-V Normally Off SiNxSiNx/AlGaN/GaN MIS-HEMT With Large Gate Swing and Low Current Collapse. IEEE Electron Device Lett. 2013, 34, 1373-1375. [CrossRef]

9. Imada, T.; Motoyoshi, K.; Kanamura, M.; Kikkawa, T. Reliability analysis of enhancement-mode GaN MIS-HEMT with gate-recess structure for power supplies. In Proceedings of the 2011 IEEE International Integrated Reliability Workshop Final Report, South Lake Tahoe, CA, USA, 16-20 October 2011; pp. 38-41. [CrossRef]

10. Anderson, T.; Wheeler, V.D.; Shahin, D.I.; Tadjer, M.J.; Koehler, A.D.; Hobart, K.D.; Christou, A.; Kub, F.J.; Eddy, C.R. Enhancement mode AlGaN/GaN MOS high-electron-mobility transistors with ZrO2gate dielectric deposited by atomic layer deposition. Appl. Phys. Express 2016, 9, 71003. [CrossRef]

11. Huang, S.; Liu, X.; Wang, X.; Kang, X.; Zhang, J.; Bao, Q.; Wei, K.; Zheng, Y.; Zhao, C.; Gao, H.; et al. High Uniformity Normally-OFF GaN MIS-HEMTs Fabricated on Ultra-Thin-Barrier AlGaN/GaN Heterostructure. IEEE Electron Device Lett. 2016, 37, 1617-1620. [CrossRef]

12. Han, P.-C.; Yan, Z.-Z.; Wu, C.-H.; Chang, E.Y.; Ho, Y.-H. Recess-Free Normally-off GaN MIS-HEMT Fabricated on Ultra-Thin-Barrier AlGaN/GaN Heterostructure. In Proceedings of the 201931st International Symposium on Power Semiconductor Devices and ICs (ISPSD), Shanghai, China, 19-23 May 2019; pp. 427-430. [CrossRef]

13. Mizue, C.; Hori, Y.; Miczek, M.; Hashizume, T. Capacitance-voltage characteristics of Al2O3/AlGaN/GaN structures and state density distribution at Al2O3/AlGaN interface. Jpn. J. Appl. Phys. 2011, 50, 021001-1-7.

14. Toyoda, S.; Shinohara, T.; Kumigashira, H.; Oshima, M.; Kato, Y. Significant increase in conduction band discontinuity due to solid phase epitaxy of $\mathrm{Al} 2 \mathrm{O} 3$ gate insulator films on GaN semiconductor. Appl. Phys. Lett. 2012, 101, 231607. [CrossRef]

15. Huang, T.; Zhu, X.; Lau, K.M. Enhancement-Mode AlN/GaN MOSHFETs on Si Substrate with Regrown Source/Drain by MOCVD. IEEE Electron Device Lett. 2012, 33, 1123-1125. [CrossRef]

16. Lu, X.; Ma, J.; Jiang, H.; Liu, C.; Xu, P.; Lau, K.M. Fabrication and Characterization of Gate-Last Self-Aligned AIN/GaN MISHEMTs With In Situ SiNx Gate Dielectric. IEEE Trans. Electron Devices 2015, 62, 1862-1869. [CrossRef] 
17. Huang, T.; Axelsson, O.; Malmros, A.; Bergsten, J.; Gustafsson, S.; Thorsell, M.; Rorsman, N. Low-PressureChemical-Vapor-Deposition SiNx passivated AlGaN/GaN HEMTs for power amplifier application. In Proceedings of the 2015 Asia-Pacific Microwave Conference (APMC), 6-9 December 2015; Institute of Electrical and Electronics Engineers (IEEE): Piscataway, NJ, USA, 2015; Volume 3, pp. 1-3.

18. Fleetwood, D.M.; Roy, T.; Shen, X.; Puzyrev, Y.S.; Zhang, E.X.; Schrimpf, R.D.; Pantelides, S.T. Oxygen-related border traps in MOS and GaN devices. In Proceedings of the 2012 IEEE 11th International Conference on Solid-State and Integrated Circuit Technology, Xi'an, China, 29 October-1 November 2012; Institute of Electrical and Electronics Engineers (IEEE): Piscataway, NJ, USA, 2012; pp. 1-4.

(C) 2020 by the authors. Licensee MDPI, Basel, Switzerland. This article is an open access article distributed under the terms and conditions of the Creative Commons Attribution (CC BY) license (http://creativecommons.org/licenses/by/4.0/). 